\title{
Syrinx associated with intramedullary metastasis
}

\author{
O FOSTER, H A CROCKARD, M P POWELL \\ From the Department of Neurology and Neurosurgery, Middlesex Hospital, London, UK
}

SUMMARY Two cases are reported of syrinx associated with an intramedullary metastasis. The first presented with hyperaesthesia in the right arm and bilateral pyramidal leg weakness, the second with a partial right sided Brown Sequard syndrome with a sensory level at D6. A possible pathological mechanism for the development of such syrinxes is discussed.

Since its description by Olliver in 1827, syringomyelia and its pathogenesis have continued to be the subject of debate. Syrinxes associated with neoplasms of spinal cord origin have long been recognised, and both the cyst cavity and the associated tumour can now be readily demonstrated with high resolution postcontrast CT scanning and magnetic resonance imaging (MRI). ${ }^{1-3}$ However, apart from Barnett's review, ${ }^{4}$ there has not been much discussion of the pathogenesis of such cysts since the 1950s.

Metastasis to the spinal cord is unusual but well described. A syrinx associated with a spinal cord secondary, found in a necropsy specimen, has previously been described. ${ }^{4}$ We report two cases of syrinx associated with an intramedullary spinal cord metastasis diagnosed during life. The pathogenesis of these lesions is discussed.

\section{Case reports}

Mr JT had undergone an anterior resection for a Duke's Stage "C" colonic adenocarcinoma in 1980 and had no evidence of systemic recurrence. He presented in November 1984 aged 66 years, with a 2 month history of mild weakness of the left arm and leg of gradual onset. He felt well, and there was no history of neck injury or neurological disorder. Examination revealed slight weakness of the left leg and a left extensor plantar response. He was followed as an outpatient and his condition remained stable for several months. His condition deteriorated in April 1985 and he presented with a one week history of rapidly progressive

Address for reprint requests: Dr Oliver Foster, Rita Lila Institute of Neurological Studies, Middlesex Hospital, Mortimer Street, London WIN8AA, UK.

Received 16 September 1986 and in revised form 15 December 1986. Accepted 23 December 1986 weakness in the right leg with associated severe pain and hyperaesthesia in the right arm. Examination revealed bilaterally brisk arm reflexes, with marked hyperaesthesia in the C5-T1 distribution on the right. There was bilateral pyramidal weakness in the legs. Bladder and bowel function were normal and anal tone preserved. The patient was admitted and a myelogram performed (fig la). A CT scan obtained the following day showed uptake of the contrast into a cystic lesion extending over the same segments (fig lb). Five days later the patient developed painful urinary retention and faecal incontinence. Examination revealed increasing deficit in his right arm and legs, an enlarged tender bladder and loss of anal tone. At operation no extradural or intradural extra-medullary pathology was noted. The spinal cord exhibited a smooth swelling extending over $4 \mathrm{~cm}$. A fine needle was passed into this and $1 \mathrm{ml}$ of clear fluid aspirated, which was indistinguishable from CSF previously obtained at myelography. Exploration confirmed a cyst cavity with a purple-grey mass in the caudal end. The mass was surrounded by oedematous spinal cord tissue and could not be excised completely. After the operation the patient developed a worsening tetraparesis, and he died in early June. Histology of the biopsy showed a poorly differentiated adenocarcinoma similar in appearance to that of the patient's bowel tumour. Post mortem examination revealed widespread metastatic disease affecting the ribs and chest wall, the abdominal lymph nodes and the body of the seventh thoracic vertebra. No intracranial deposits were found. Sections of the spinal cord showed cavitation in the upper cervical region with intramedullary tumour.

Miss BD had undergone a right sided Patey mastectomy followed by radiotherapy in 1982 for poorly differentiated adenocarcinoma. She presented in October 1985 aged 55 years with 3 months history of slight weakness in the right leg with decreased awareness of heat in the left leg. She had also noticed decreased bladder sensation. Examination at that time showed decreased power in the right leg flexors and a mild sensory level for pin-prick on the left at D6. A myelogram showed a fusiform swelling of the cord in the mid-thoracic region and she was treated with local radiotherapy and oral tamoxifen on the presumptive diagnosis of 

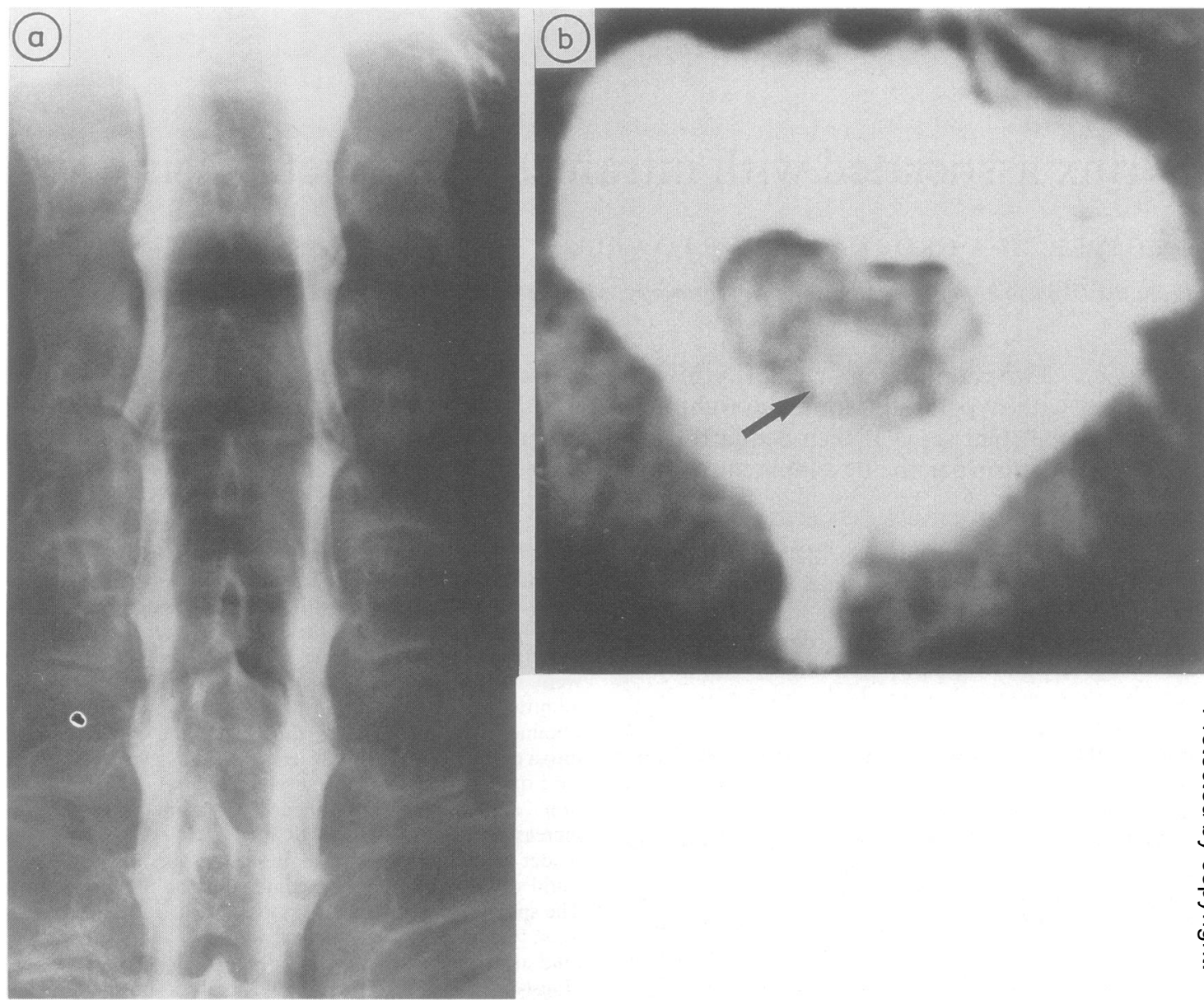

Fig 1 (a) Metrizamide myelogram showing smooth fusiform expansion of the cervical cord extending from C3 to C6 with no evidence of an extramedullary lesion. (b) CT scan at C4 level performed 24 hours after myelography, showing metrizamide uptake in the centre of the cord (arrow), and residual contrast in the subarachnoid space.

a cord metastasis. After initial symptomatic improvement, her condition deteriorated rapidly in December of 1985 despite high dose dexamethasone treatment. Examination revealed bilateral sensory loss from D6 downwards in all modalities, with a more severe deficit to pin-prick on the left and to joint position sense on the right. Power was reduced bilaterally, more so on the right, and there was right sided hyperreflexia with an extensor plantar response. An MRI scan (fig 2a) showed an intramedullary cyst extending from C6-D10 with no evidence of focal tumour. Immediately prior to operation there was no movement in the right leg and grade III power in the left. A decompressive laminectomy was performed at D6 in January 1986. The dura was found to be slack and pulsating. The cord appeared slightly swollen in a fusiform fashion, as suggested by the original myelogram. The cord was opened in the midline and a cystic cavity discovered. This was followed upwards for a few millimetres and a substantial $15 \mathrm{~mm}$ metastatic deposit of gritty consistency was found, typical of CNS breast deposits. The tumour was removed macroscopically in toto leaving an attenuated oedematous cord. Histology confirmed the presence of metastatic adenocarcinoma compatible with the patient's breast tumour. She made a good post-operative recovery. A second course of radiotherapy was given and she was referred for rehabilitation. On transfer she had marginal improvement in her left leg strength, but her right leg remained weak. She was subsequently able to walk with a frame, but deteriorated 4 months after surgery with weakness in both arms. Examination revealed decreased light touch and pinprick sensation at $\mathrm{C} 8$ and motor weakness in a C8-Tl distribution. A further MRI study showed rostral extension of the syrinx (fig $2 b$ ). At a second surgical procedure a shunt was inserted into the syrinx with some symptomatic improvement. However the patient deteriorated a few weeks later and died of the effects of cerebral secondaries. 

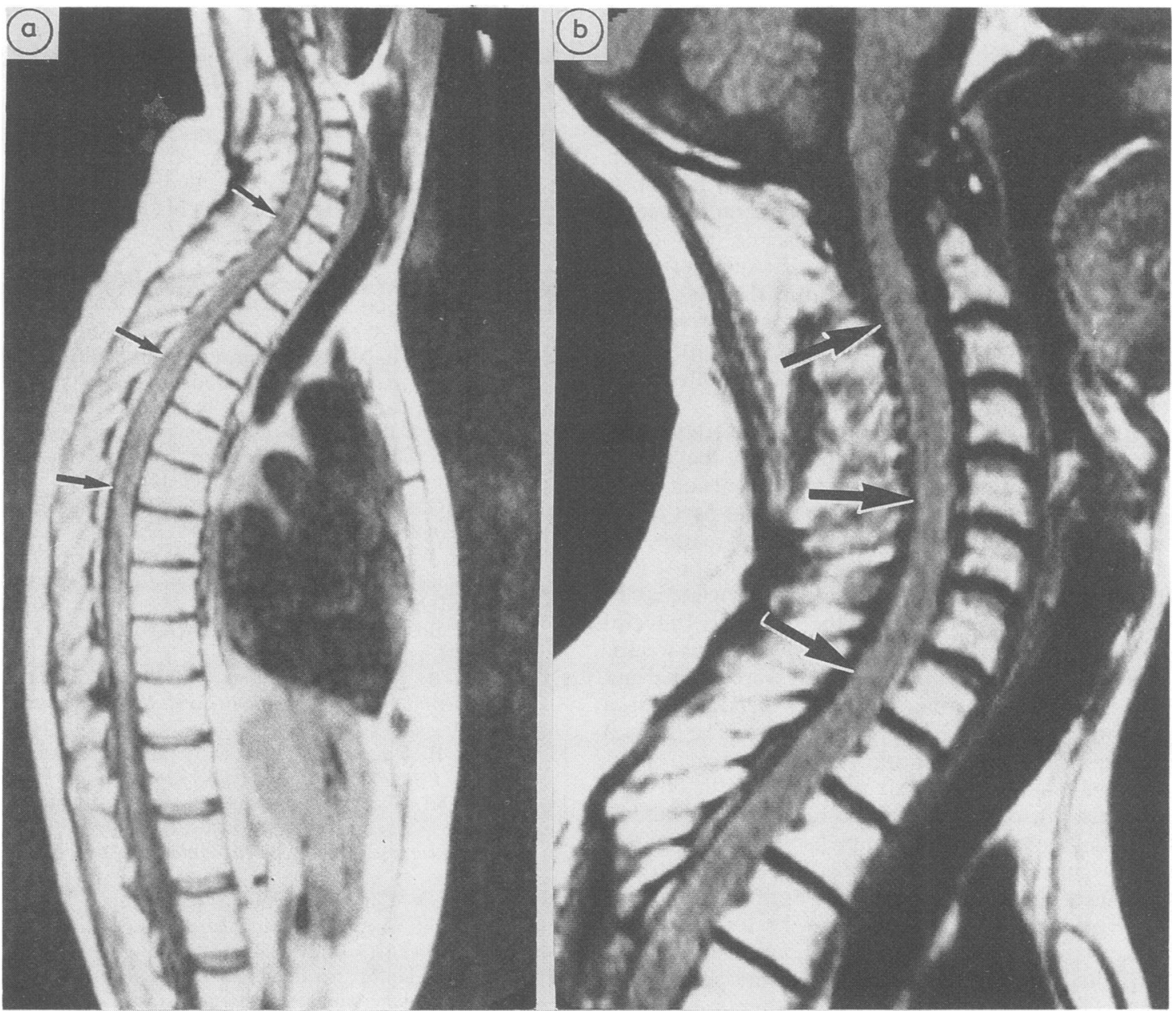

Fig 2 (a) MRI scan showing an intramedullary cyst extending from C6 to D10 with no evidence of focal tumour. (b) MRI scan showing the intramedullary cyst extending from $C 2$ down.

\section{Discussion}

Imaging, operative findings and histological examination confirmed the presence of metastasisassociated syrinx in these patients. Weitzner, in 1969, made the only previous report of such a finding, in a neurologically asymptomatic patient. ${ }^{5}$ He concluded that the syrinx could have predated the metastasis, since there was no clue from the history. In our cases, the history suggests that syrinx formation was of recent origin, presumably secondary to the metastasis. This finding may give a clue to the pathogenesis of some tumour related "non-communicating" syrinxes.

In the first half of this century, many believed that spinal cord tumours and all syrinxes were aspects of a common process. ${ }^{6-8}$ Syrinx formation was thought to be secondary to metaplasia of the spinal cord, evidenced by glial proliferation in the cavity wall. Such gliosis is now considered to be secondary to syrinx formation, and discussion has for many years concentrated on two hypotheses: that syrinx formation results from ischaemic necrosis of the central cord, either as a primary event or secondary to adhesive arachnoiditis involving the meningeal vessels; ${ }^{79}$ or, that a disturbance of CSF dynamics allowed the cord to be split by pressure waves. ${ }^{1011}$ While the latter is a most attractive explanation of "communicating" syringomyelia and has experimental support, ${ }^{12}$ it cannot readily explain syrinx formation in association with spinal cord tumour. Barnett in $1972^{4}$ and Will- 
iams in $1980^{13}$ could not discount the old theory of metaplasia as an explanation of syrinx formation related to primary tumours, but the association of such cavities with metastatic cord tumours cannot be accounted for in this way.

Pencil-shaped softening of the central cord often with a cystic component is well described in association with spinal cord trauma ${ }^{14}$ and extradural compression either from spondylosis, or extradural metastasis. ${ }^{15}$ Jellinger considered that such softening was of vascular origin and was an early stage in the formation of post traumatic syrinxes. There have been several recent reports of such pencil-shaped softening (although without mention of a cyst) in association with intramedullary metastasis. ${ }^{16-18}$

Hashizume et al ${ }^{1518}$ reported such softening in three out of five cases of intramedullary metastasis. The changes extended over several segments on either side of the tumour deposit; in the ventral part of the posterior columns and the central grey matter, the same area as is affected in post traumatic cases. Hashizume et al's three cases were all associated with bronchial carcinoma and the average interval between symptom onset and death was seven weeks.

In our cases the primary tumours were colonic and mammary adenocarcinoma, which tend to run a slower course than bronchial carcinoma. The interval between the onset of symptoms and surgical intervention was more than six months in both of these patients, far longer than in Hashizume et al's cases.

It may be that "pencil-shaped softening", possibly of vascular aetiology preceded cavitation in the genesis of the syrinxes we report.. Syrinxes associated with primary cord tumours may be formed in the same way, rather than by fluid exudation as has been suggested. ${ }^{1319}$ Syrinxes associated with spinal cord metastasis have not previously been reported during life, perhaps because intramedullary metastasis usually occurs in the context of rapidly fatal disseminated disease. ${ }^{16-18}$ However, our observation of two cases in the last year suggests that recent advances in spinal cord imaging with the more active surgical approach they allow, will bring to light an increasing number of such cases in the future.

\section{References}

1 Aubin ML, Vignaud J, Jardin C, Bar D. Computed tomography in 79 clinical cases of syringomyelia.
AJNR 1981;2(3):199-204.

2 Kan S, Fox AJ, Vinuela F, Barnett HJ, Peerless SJ. Delayed CT metrizamide enhancement of syringomyelia secondary to tumour. AJNR 1983;4(1):73-8.

3 Lee BC, Deck MD, Kneeland JB, Cahill PT. NMR imaging of the craniocervical junction. AJNR 1985;6(2):209-13.

4 Barnett HJM, Rewcastle MB. Syringomyelia and tumours of the nervous system. In: Barnett HJM, Foster JB, Hudgson P. Syringomyelia. London: WB Saunders, 1973:261-301.

5 Weitzner S. Coexistant metastasis and syringomyelia of the cervical cord. Neurology 1969;19:675-8.

6 Jonesco-Sisesti N. La Syringobulbie. In: Libraires de L'Academie de Medecine. Paris: Masson, 1932:261-9.

7 Tauber ES, Langworty OR. A study of syringomyelia and the formation of cavities in the spinal cord. J Nerv Ment Dis 1935:81:245-64.

8 Poser CM. The Relationship between Syringomyelia and Neoplasm. Illinois: Thomas Springfield, 1956.

9 Netsky MG. Syringomyelia: a clinicopathological study. Arch Neurol Psychiatry 1953;70:741-77.

10 Gardener WJ. Hydrodynamic mechanism of syringomyelia: its relationship to myelocoele. J Neurol Neurosurg Psychiatry 1965;28:247-59.

11 Williams B. Current concepts of syringomyelia. $\mathrm{Br} J$ Hosp Med 1970;4:331-42.

12 Williams B, Weller RO. Syringomyelia produced by intramedullary fluid injection in dogs. J Neurol Neurosurg Psychiatry 1973;36:467-77.

13 Williams B. On the pathogenesis of syringomyelia: a review. Proc $R$ Soc Med 1980;73:798-806.

14 Jellinger KI. Traumatic vascular disease of the spinal cord. In: Vinken PJ, Bruyen G, eds. Handbook of Clinical Neurology. Vol 12. North Holland: Amsterdam, 556-630.

15 Hashizume Y, Iljima S, Kishimoto H, Hirano A. Pencilshaped softening of the spinal cord. Acta Neuropathol (Berl) 1983;61(3-4):219-24.

16 Jellinger KI, Kothbauer P, Sunder-Plassman E, Weiss R. Intramedullary spinal cord metastasis. J Neurol 1979;220(1):31-41.

17 Hirose G, Shimazaki K, Takado M, Kosoegwa H, Ohya N, Mukawa A. Intramedullary spinal cord metastasis associated with pencil-shaped softening of the spinal cord. J Neurosurg 1980;52:718-21.

18 Hashizume Y, Hirano A. Intramedullary spinal cord metastasis. Pathological findings in five autopsy cases. Acta Neuropathol (Berl) 1983;61(3-4):214-8.

19 Laroche JC. Malformation of the nervous system. In: Hume Adams J, Corsellis JAN, Duchen LW, eds. Greenfield's Neuropathology 4th Ed. London: Edward Arnold, 1984:400-2. 